\title{
Intravenous Carbetocin to decrease blood loss during open myomectomy: a randomized placebo-controlled study
}

\author{
Hany F. Sallam*, Nahla W. Shady
}

Department of Obstetrics and Gynecology, Faculty of Medicine, Aswan University, Egypt

Received: 21 October 2017

Accepted: 17 November 2017

\section{*Correspondence:}

Dr. Hany F. Sallam,

E-mail: hany.farouk@aswu.edu.eg

Copyright: (C) the author(s), publisher and licensee Medip Academy. This is an open-access article distributed under the terms of the Creative Commons Attribution Non-Commercial License, which permits unrestricted non-commercial use, distribution, and reproduction in any medium, provided the original work is properly cited.

\begin{abstract}
Background: Uterine leiomyomas are benign tumors of the uterus, which represent the most common neoplasms in women of reproductive age, and have a lifetime incidence of approximately $70 \%$ in the general population. The objective of this study was to assess the effect of using a single pre-operative dose of IV $100 \mu \mathrm{g}$ Carbetocin on intraoperative blood loss in abdominal myomectomy surgeries.

Methods: In a randomized double-blind placebo-controlled trial, 86 women undergoing abdominal myomectomy for symptomatic uterine leiomyomas were randomly assigned to receive a single dose of pre-operative of IV $100 \mu \mathrm{g}$ Carbetocin $(n=43)$ or placebo $(n=43)$ just before the operation. The primary outcome was intra-operative blood loss.

Results: Intra-operative blood loss was significantly lower in those women randomized to receive IV Carbetocin versus the placebo group $(714.19 \pm 186.27 \mathrm{ml}$ versus $1033.49 \pm 140.9 \mathrm{ml}), \mathrm{p}=0.0001$ The incidence of blood transfusion was increased in placebo group $(69.8 \%)$ compared with $(18.6 \%)$ in Carbetocin group, $(\mathrm{P}=0.0001)$. Also, there was a significant reduction in operative time in Carbetocin group $(66.35 \% \pm 10.18)$ compared with placebo group (95.95 \pm 9.16$),(\mathrm{P}=0.0001)$.

Conclusions: A single pre-operative dose of IV Carbetocin $(100 \mu \mathrm{g})$ is a simple applicable method for reducing intraoperative blood loss and operative time in abdominal myomectomy.
\end{abstract}

Keywords: Carbetocin, Myomectomy

\section{INTRODUCTION}

Uterine leiomyomas are benign tumors of the uterus, which represent the most common neoplasms in women of reproductive age, and have a lifetime incidence of approximately $70 \%$ in the general population. ${ }^{1}$ Approximately $20-40 \%$ of women with fibroids experience significant symptoms and consult gynaecologic care. ${ }^{1}$ The most common clinical symptoms include abnormal uterine bleeding, dysmenorrhea, pelvic pain, infertility, and recurrent pregnancy loss. ${ }^{1}$

Currently, there are several strategies for the treatment of fibroids, but myomectomy remains the most common and the most efficient uterus-sparing treatment. ${ }^{2}$ Nevertheless, this procedure is associated with known risks, chief of which is excessive peri- or post-operative blood loss which sometimes necessitates hysterectomy.

The risk of bleeding depends on the number, the size and the position of fibroids removed. To reduce intraoperative hemorrhage, many interventions have been proposed to reduce bleeding and blood transfusion. ${ }^{3}$

The role of oxytocin on hemostasis can be best appreciated with its commonplace obstetric use in achieving hemostasis after delivery and preventing postpartum hemorrhage. focusing on its known 
physiologic role of stimulating uterine contraction via its action on smooth muscle cells, oxytocin's utility in attenuating blood loss during myomectomies has been evaluated in multiple research studies. ${ }^{4}$

Although the expression of oxytocin receptors is believed to be strictly related to pregnancy, their presence has recently been being demonstrated in leiomyomata's uterus. $^{5}$

The first randomized placebo control study on the use of oxytocin was carried out in 2005. Ninety-four patients were randomized to receive oxytocin during open myomectomy. The protocol adopted was $15 \mathrm{UI}$ dissolved in $125 \mathrm{ml}$ of normal saline solution. There was no significant difference in terms of perioperative blood loss and transfusion rate between placebo and treated group. ${ }^{6}$ Conversely, the infusion of oxytocin at a rate of 40 $\mathrm{mu} / \mathrm{ml}$ during laparoscopic myomectomy seems to have beneficial effects. $^{7}$

Nevertheless, oxytocin has a short half-life (4-10 minutes), necessitating continuous intravenous infusion. Moreover, saturation of myometrial oxytocin receptors could reduce its effectiveness, and excessive dosing can lead to coronary-artery contraction and hypotension; additionally, water intoxication can occur owing to its anti-diuretic effects. ${ }^{8}$

Carbetocin is a long-acting synthetic analogue of oxytocin that can be administered as a single-dose injection, either intravenously or intramuscularly. ${ }^{9}$ Intravenously administered Carbetocin has a half-life of approximately 40 minutes, around 4-10 times longer than that reported for oxytocin. ${ }^{9}$

Following intramuscular injection, Carbetocin reaches peak plasma concentrations in less than 30 minutes and has $80 \%$ bioavailability. ${ }^{9}$ Carbetocin onset of action is rapid irrespective of administration route, but duration of action is longer following intramuscular injection. The optimal Carbetocin dose (intravenous or intramuscular) is $100 \mu \mathrm{g} .{ }^{10}$

The aim of this study was to assess the effect of using a single pre-operative dose of IV $100 \mu \mathrm{g}$ Carbetocin on intra-operative blood loss in abdominal myomectomy surgeries.

\section{METHODS}

This study was a double blinded randomized controlled study in two parallel groups, with intervention and placebo allocation ratio $1: 1$, conducted in Aswan university, Egypt from May 2015 to May 2017.

\section{Inclusion criteria}

Women who attended the Outpatient Gynecology clinic, seeking treatment for symptomatic leiomyomas and scheduled to undergo abdominal myomectomy with number of myoma not exceeding five and staging of myoma from (3 to 6 ) according to FIGO staging. ${ }^{11}$

\section{Exclusion criteria}

- Patients undergone vaginal or laparoscopic myomectomy.

- Patients received preoperative embolization or Gn$\mathrm{Rh}$ analogue.

- Cervical and broad ligament myoma.

- Number of myoma more than five.

- $\quad$ Myoma FIGO staging (1,2,7 and 8). ${ }^{11}$

The participants who fulfilled the eligibility criteria were explained about the study. Informed consent was obtained from them, one hundred patients were invited for the study, eleven not meeting inclusion criteria and three refused to participate therefor eighty-six patients were included in the study. All participants undergone detailed history, general, abdominal and vaginal examinations, body mass index (BMI) was calculated and pelvic ultrasound examination was undertaken for all participants to assess the number and location of myomas and the largest myoma diameter.

\section{Randomization}

Patients were randomized to study and placebo groups, each compromised of forty-three patients according to a two-blocked randomization list which was coded (1 or 2) at $1: 1$ ratio. The two parallel groups were prepared using a Computer-generated randomization system.

The allocated groups will be concealed in serially numbered sealed opaque envelopes that will only be opened after recruitment. Patient allocation will be performed prior to the induction of anesthesia by an independent person, who will not otherwise be involved in this study.

The trial will be appropriately blinded; the participants, outcome assessors and the surgeon performing the procedure will be blinded to the medication type, which will be used.

\section{Intervention}

Eligible participants were allocated to one of two groups after induction of spinal anesthesia and immediately prior to the operation. The Carbetocin group received $100 \mu \mathrm{g}$ IV Carbetocin (1ml) [Pabal, Ferring (UK)] in $5 \mathrm{ml}$ saline just before skin in scion. The placebo group received 5 $\mathrm{ml}$ IV pure normal saline just before skin incision. In all operations, the abdomen was exposed through a Pfannensteil incision, abdominal myomectomy was performed then the uterine incision was repaired by twolayer suturing by the same gynecological surgeon team, who were all blinded to the medication given. 


\section{Blood loss estimation}

Intraoperative blood loss was measured by adding the volume of the contents of the suction bottle and the difference in weight (in grams) between the dry and the soaked operation sheets and towels $(1$ gram $=1 \mathrm{ml}$.).

\section{Study outcome}

The primary outcome was estimation of intraoperative blood loss (ml). The secondary outcome measures included need for blood transfusion, operative time, period for hospitalization. Also, Hemoglobin concentration was done in all patients preoperative and 24 hours postoperative and the change in concentration was noted. Any side effects were recorded.

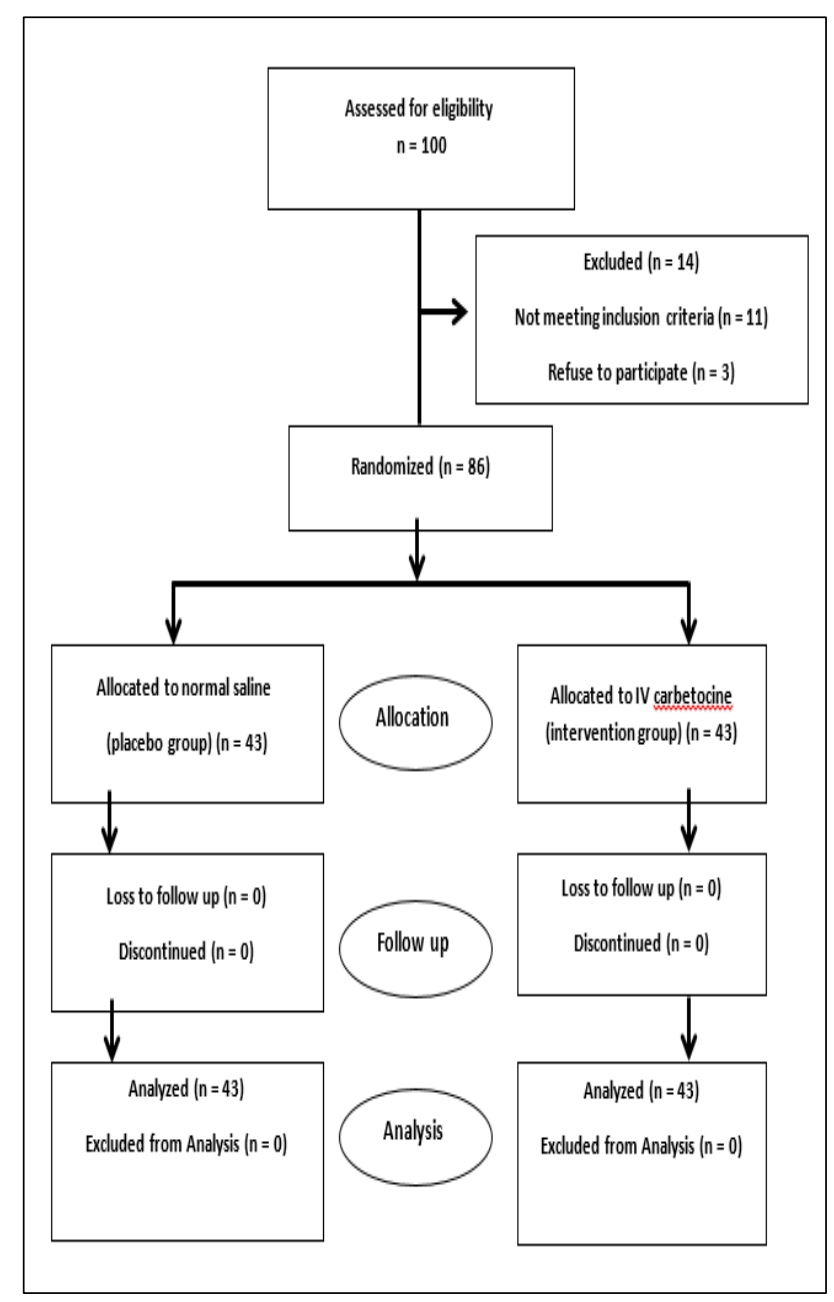

Figure 1: The study flowchart.

\section{Statistically analysis}

The data were entered and statistically analyzed using the Statistical Package for Social Sciences (SPSS) version 16. Qualitative data were described as numbers and percentages. Chi-square test was used for comparison between groups. Quantitative data were described as means (SD) or medians, as appropriate. They were tested for normality by Kolmogorov-Smirnov test. In the normally distributed variables, independent sample t-test was used for comparison between groups. In the nonnormally distributed variables, Mann-Whitney test was used for comparison between groups. Odds ratios and their $95 \%$ confidence interval were calculated. "p value $\leq 0.05$ " was considered to be statistically significant.

\section{RESULTS}

Present study started with 100 patients who were asked to participate, 14 patients were excluded, 11 patients not meeting inclusion criteria and 3 patients refuse to participate. The remaining 86 patients with, 43 patients randomized to Carbetocin (study group) and 43 patients to placebo (control group) were included in the final analysis.

There was no significant difference between the two groups with respect to their age, weight, height, body mass index (BMI), parity, myoma number, myoma stage, size of the largest myoma, uterine size and history of previous scar (Table 1).

There was high significant reduction in intraoperative blood loss in Carbetocin group (714.19 \pm 186.27$)$ compared with placebo group (1033.49 \pm 140.9) $(\mathrm{P}=0.0001)$.

The incidence of blood transfusion was increased in placebo group $30(69.8 \%)$ patients compared with 8 (18.6\%) patients in Carbetocin group, $(\mathrm{P}=0.0001)$.

Also, there was a highly significant reduction in operative time in Carbetocin group $(66.35 \% \pm 10.18)$ compared with placebo group $(95.95 \pm 9.16),(\mathrm{P}=0.0001)$.

There was no significant difference in related to initial hemoglobin concentration between the two groups, however there was a reduction in 24-hour post-operative hemoglobin concentration in placebo group than Carbetocin group, but this reduction not reach the significant difference, $(\mathrm{P}=0.069)$.

Finally, no significant difference between the two groups in related to their hospital stay, $(\mathrm{P}=0.514)$. (Table 2$)$

\section{Study power calculation}

As the average amount of blood loss was the primary outcome of this research, study power was calculated online (www.dssresearch.com) using the average value of the intervention group $(714.2 \pm 186.3)$ and that of the control group $(1033.5 \pm 140.9)$, the sample size was 43 for each group with $95 \%$ confidence level. The study power was found to be $100 \%$. 
Table 1: Demographic criteria of the study groups.

\begin{tabular}{|c|c|c|c|}
\hline Characteristics & Placebo group $(n=43)$ & Carbetocine group $(n=43)$ & Significance \\
\hline Age & $34.49 \pm 4.39$ & $34.84 \pm 4.41$ & 0.714 \\
\hline Weight & $67.77 \pm 7.11$ & $68.19 \pm 6.51$ & 0.777 \\
\hline Height & $163.14 \pm 4.1$ & $163.16 \pm 4.12$ & 0.979 \\
\hline BMI & $25.43 \pm 2.06$ & $25.58 \pm 2$ & 0.729 \\
\hline Parity & $2(0-5)$ & $2(0-4)$ & 0.781 \\
\hline Myoma number & $3(1-5)$ & $3(1-5)$ & 0.454 \\
\hline \multicolumn{4}{|l|}{ Myoma stage } \\
\hline 3 & $9(20.9)$ & $8(18.6)$ & \multirow{4}{*}{0.979} \\
\hline 4 & $11(25.6)$ & $10(23.3)$ & \\
\hline 5 & $9(20.9)$ & $10(23.3)$ & \\
\hline 6 & $14(32.6)$ & $15(34.9)$ & \\
\hline Size of the largest myoma & $13.09 \pm 3.85$ & $13.21 \pm 3.41$ & 0.882 \\
\hline Uterine size & $20.6 \pm 4.04$ & $20.75 \pm 3.6$ & 0.866 \\
\hline Pervious scar & $14(32.6)$ & $15(34.9)$ & 0.820 \\
\hline
\end{tabular}

Table 2: Peri-operative variables in the study groups.

\begin{tabular}{|lll|l|}
\hline Variables & Placebo grouj, $(\mathbf{n}=\mathbf{4 3})$ & Carbetocine group, $(\mathbf{n}=\mathbf{4 3})$ & Significance \\
\hline Initial Hemoglobin & $10.69 \pm 0.89$ & $10.73 \pm 0.85$ & 0.843 \\
\hline Post-operative hemoglobin & $9.87 \pm 0.77$ & $10.18 \pm 0.78$ & 0.069 \\
\hline Blood loss & $1033.49 \pm 140.9$ & $714.19 \pm 186.27$ & $0.0001^{*}$ \\
\hline Blood transfusion & $30(69.8)$ & $8(18.6)$ & $0.0001^{*}$ \\
\hline Operative time & $95.95 \pm 9.16$ & $66.35 \pm 10.18$ & $0.0001^{*}$ \\
\hline Hospital Stay & $3.49 \pm 0.83$ & $3.37 \pm 0.82$ & 0.514 \\
\hline
\end{tabular}

Variables are presented as mean \pm standard deviation, median (minimum-maximum) and number (percentage); * Statistically significant.

\section{DISCUSSION}

Open myomectomy remain the main option has been shown to have satisfactory result as regard fertility preservation and symptom resolution with specially when the number and size of leiomyomas do not permit any other surgical rout of the surgery. Hemorrhage remains the most important concern with open myomectomy. Blood loss during surgery largely depends on the number and size of the fibroids removed and the technique adopted during myomectomy. ${ }^{3}$

Various techniques are available to reduce intra-operative bleeding, but differences in patient characteristics make any comparison of efficacy difficult. Consequently, there is still no agreement on the preferred method of hemostasis. $^{7}$

To the best of our knowledge this randomized, doubleblinded study was the first designed to specifically compare the effect of Carbetocin $(100 \mu \mathrm{g}) \mathrm{IV}$ in reduce the blood loss during open myomectomy

In this study, the mean blood loss in the placebo group was $1033 \mathrm{~mL}$ and $714 \mathrm{~mL}$ in the study group. This demonstrates IV Carbetocin was associated with a mean reduction in blood loss of $310 \mathrm{ml}$.
In concordance with the present results Yang $\mathrm{M}$, et al compare Carbetocin versus Oxytocin in decrease blood loss during laparoscopic myomectomy and concluded that giving Carbetocin preoperatively to laparoscopic myomectomy patients had good clinical efficacy, bringing about less blood loss, shorter operative time and rapid postoperative recovery. It is, therefore considered safe and reliable and worthy of clinical applications. ${ }^{12}$

Also, Allah G et al study the effect of intra-myometrial Carbetocin injection in reducing intraoperative blood loss during myomectomy and conclude that Injection of intramyometrial Carbetocin was associated with less blood loss during myomectomy. Moreover, it may lower the need for blood transfusion. Patients in whom Carbetocin was used showed lower drop in their hemoglobin and hematocrit levels when measured 48 hours postoperatively. ${ }^{13}$

There are some reports of a positive effect on several outcomes after Carbetocin for prevention of post-partum hemorrhage after cesarean section and vaginal delivery. However, there was a paucity of information regarding the efficacy of a IV Carbetocin for reduce blood loss during myomectomy. ${ }^{14,15}$ 
Carbetocin is a newer agent that can potentially provide the benefit of longer acting maintenance of oxytocic action without the need for prolonged infusion

Carbetocin was initially developed in the 1970s as a veterinary product; it is a long-acting synthetic octapeptide analogue of oxytocin (which is a nonapeptide) with agonist properties at the oxytocin receptor. Structural differences to oxytocin include replacement of the amino-group of cysteine by a hydrogen atom, modification of the disulphide bond by a thio-ether bond and a substitution of the hydroxyl group of tyrosine by a methyloxyl group. These molecular changes give Carbetocin more stability and avoid early decomposition by disulphidase, aminopeptidase and oxidoreductase enzymes. ${ }^{16}$ The pharmacodynamic properties of Carbetocin are comparable to those of endogenous oxytocin. Carbetocin selectively binds to oxytocin receptors in the smooth muscle of the uterus resulting in rhythmic uterine contractions, increased frequency of existing contractions, and increased uterine tone. ${ }^{17}$ Since the half-life of oxytocin is only 10 to 15 minutes, synthetic long-lasting oxytocin agonistic analogs have been synthesized. In particular, 1-desamino-1monocarbo-(2-O-methyltyrosine)-oxytocin (carbetocin) shows structural modifications that increase its half-life, that is, by 40 minutes, and prolonging its pharmacological effects in terms of myometrial contractility. ${ }^{18}$ Carbetocin binds selectively to OXTRs in the uterine smooth muscle. It is able both to stimulate uterine rhythmic contractions, increasing the frequency of already present contractions, and to raise the tone of the uterine muscle. It can be administered as a single-dose injection, either intravenously or intramuscularly. ${ }^{19}$ Rhythmic uterine contractions continue for 60 minutes after the intravenous injection and for 120 minutes after the intramuscular administration. Currently, a dosage of $100 \mathrm{mg}$ of Carbetocin is used for the prevention of $\mathrm{PPH}^{20}$

In the present study, we compared the pre-operative and postoperative hemoglobin and as secondary outcomes observing the change in hemoglobin and was lower in the study group but not reach statistical significance. Gad Allah et al showed in their study significant decrease of post-operative HB in control group. ${ }^{13}$

In the present study operative time and blood transfusion is statistically significant decrease in the Carbetocin group. This result was in concordance with Allah $\mathrm{G}$ et al and Yang, et al. ${ }^{12,13}$

One of the strength of the present study was that double blind randomized study provides the first evidence that a IV Carbetocin a simple alternative preemptive intervention for reduced intraoperative blood loss and need of blood transfusion during abdominal myomectomy. Another strength of the present study as the average amount of blood loss was the primary outcome of this research, study power was calculated online was found to be $100 \%$.
One limitation of the present study was that we did not used alkaline hematin method which is a validated method for accurate measurement of blood loss, but instead we used a gravimetric method to measure the amount of blood loss. ${ }^{21}$ However Marcel $\mathrm{H}$ et al in veterinary surgery compare gravimetric and colorimetric methods of quantifying surgical blood loss and conclude that estimation of blood loss using a gravimetric method is accurate and $\mu$ objective tool to evaluate intraoperative blood loss. ${ }^{22,24}$

\section{CONCLUSION}

A single pre-operative dose of IV Carbetocin is a simple, cost effective method for reducing intra-operative blood loss and operative time in abdominal myomectomy. Investigation of Carbetocin use in larger population groups and with different dosages and another route together with comparison of other methods used to reduce bleeding during myomectomy, is required.

Funding: No funding sources

Conflict of interest: None declared

Ethical approval: The study was approved by the Institutional Ethics Committee

\section{REFERENCES}

1. Marsh EE, Ekpo GE, Cardozo ER, Brocks M, Dune $\mathrm{T}$, Cohen LS. Racial differences in fibroid prevalence and ultrasound findings in asymptomatic young women (18-30 years old): a pilot study. Fertility and Sterility. 2013;99(7):1951-7.

2. Taylor A, Sharma M, Tsirkas P, Di Spiezio Sardo A, Setchell M, Magos A. Reducing blood loss at open myomectomy using triple tourniquets: a randomized controlled trial. Br J Obstet Gynaecol. 2005;112:3405.

3. Kongnyuy EJ, Wiysonge CS. Interventions to reduce haemorrhage during myomectomy for fibroids. Cochrane Database Syst Rev. 2011:Cd005355.

4. Atashkhoei S, Fakhari S, Pourfathi H, Bilehjani E, Garabaghi PM, Asiaei A. Effect of oxytocin infusion on reducing the blood loss during abdominal myomectomy: a double-blind randomised controlled trial. BJOG. 2016;124:292-8

5. Busnelli M, Rimoldi V, Vigano P, Persani L, Di Blasio AM, Chini B. Oxytocin-induced cell growth proliferation in human myometrial cells and leiomyomas. Fertil Steril. 2010;94:1869-74.

6. Agostini A, Ronda I, Franchi F, Bretelle F, Roger V, Cravello L, et al: Oxytocin during myomectomy: a randomized study. Eur J Obstet Gynecol Reprod Biol 2005;118:235-8.

7. Wang CJ, Lee CL, Yuen LT, Kay N, Han CM, Soong YK. Oxytocin infusion in laparoscopic myomectomy may decrease operative blood loss. J Minim Invasive Gynecol. 2007;14:184-8. 
8. Rath W. Prevention of postpartum hemorrhage with the oxytocin analogue carbetocin. Eur J Obstet Gynecol Reprod Biol. 2009;147(1):15-20.

9. Sweeney SG, Holbrook AM, Levine M, Yip M, Alfredsson K, Cappi S, et al. Pharmacokinetics of carbetocin, a long-acting oxytocin analogue, in nonpregnant women. Current Therapeutic ResearchClinical and Experimental. 1990;47(3):528-40.

10. van Dongen PW, Verbruggen MM, de Groot ANJA, van Roosmalen J, Sporken JMJ, Schulz M. Ascending dose tolerance study of intramuscular Carbetocin administered after normal vaginal birth. Eur J Obstet Gynecol Reprod Biol. 1998;77:181-7.

11. Munro MG, Critchley HO, Broder MS, Fraser IS. FIGO classification system (PALM-COEIN) for causes of abnormal uterine bleeding in non-gravid women in the reproductive years. Int $\mathbf{J}$ Gynaecol Obstet. 2011;113:3-13.

12. Yang $M$, Wu $C$, Wen $X$, Lin $M$, Li L. Using Carbetocin to prevent hemorrhage in laparoscopic myomectomy. 2012;6(27):2023-6.

13. Allah G, Sherine H, Wali A, Mostafa A, Shimaa. Hemostatic effect and postoperative benefits of intramyometrial Carbetocin injection during myomectomy: a randomized controlled trial. Evidence Based Women's Health J. 2015;5(4):185-9.

14. Su LL, Chong YS, Samuel M. Carbetocin for preventing postpartum haemorrhage. Cochrane Database of Systematic Reviews. 2012;4.

15. Meshykhi LS, Nel MR, Lucas DN. The role of Carbetocin in the prevention and management of postpartum hemorrhage. Int J Obstet Anesthesia. 2016;28:61-9.
16. Sweeney G, Holbrook AM, Levine M. Pharmacokinetics of carbetocin, a long-acting oxytocin analogue, in non-pregnant women. Curr Ther Res Clin Exper. 1990;47:528-539

17. Hunter DJ, Schulz P, Wassenaar W. Effect of carbetocin, a long-acting oxytocin analog on the postpartum uterus. Clin Pharmacol Ther. 1992;52:60-7.

18. Peters NC, Duvekot JJ. Carbetocin for the prevention of postpartum hemorrhage: a systematic review. Obstet Gynecol Surv. 2009;64(2):129-35.

19. Engstrom T, Barth T, Melin P, Vilhardt H. Oxytocin receptor binding and uterotonic activity of Carbetocin and its metabolites following enzymatic degradation. Eur J Pharmacol. 1998;355(2-3):20310.

20. Rath W. Prevention of postpartum hemorrhage with the oxytocin analogue carbetocin. Eur J Obstet Gynecol Reprod Biol. 2009;147(1):15-20.

21. Larsson C, Saltvedt S, Wiklund I. Estimation of blood loss after caesarean section and vaginal delivery has low validity with a tendency to exaggeration. Acta Obstet Gynecol Scand. 2006;85:1448-52.

22. Lee MH, Ingvertsen BT, Kirpensteijn J, Jensen AL, Kristensen AT. Quantification of surgical blood loss. Vet Surg. 2006;35(4):388-93.

Cite this article as: Sallam HF, Shady NW. Intravenous Carbetocin to decrease blood loss during open myomectomy: a randomized placebo-controlled study. Int J Reprod Contracept Obstet Gynecol 2018;7:27-32. 